http://jmscr.igmpublication.org/home/

ISSN (e)-2347-176x ISSN (p) 2455-0450

crossref DOI: https://dx.doi.org/10.18535/jmscr/v9i7.07

Journal Of Medical Science And Clinical Research

IGM Publication

An Official Publication of IGM Publication

\title{
Sirenomelia: A Rare Interesting Case of Mermaid Baby Syndrome
}

\author{
Authors \\ Dr Manvi Katoch ${ }^{1}$, Dr Tanvi Katoch ${ }^{2}$ \\ ${ }^{1}$ Anaesthesiologist, Zonal Hospital, Dharamshala, H.P. \\ ${ }^{2}$ Senior Resident, Department of Obstetrics and Gynecology, PGI, Chandigarh \\ *Corresponding Author \\ Dr Tanvi Katoch \\ Senior Resident, Department of Obstetrics and Gynecology, PGI, Chandigarh
}

\begin{abstract}
Sirenomelia is a congenital disorder of multiple malformations that includes a fusion of the lower limbs giving a mermaid-like appearance to the affected fetus. We report a case of sirenomelia occurring in a 30year-old woman who had early-onset severe oligohydramnios, and the syndrome was diagnosed during the baby's delivery.

Keywords: sirenomelia, mermaid-like tail, renal agenesis, lower limb fusion.
\end{abstract}

\section{Introduction}

Sirenomelia is a rare, often fatal, congenital malformation disorder ${ }^{[1]}$. Its incidence is approximately about 1 in 100,000 pregnancies $^{[2]}$. Predominantly, it affects males more than females $^{[3]}$. It is named sirenomelia because the fetus or the newly born baby has a striking resemblance to the mermaid of Greek mythology: a living entity with the head and thorax of a human and the lower portion of a human fish with fins and tail. The anomaly occurs due to the complete or partial fusion of the lower limbs into a single lower limb.

The syndrome is associated with multiple other visceral anomalies that make the syndrome incompatible with life ${ }^{[4]}$, but there are reported cases of surviving infants.

We report a rare case of sirenomelia in India, born still to a 30-year-old woman.

\section{Case Report}

30-year-old G3P0020 presented to our centre in the outpatient department with absent liquor at 32 weeks of gestation. She had been married for 6years and had a history of two spontaneous firsttrimester abortions. She conceived by ovulation induction in this pregnancy; her anomaly scan at 17 weeks gestation showed absent liquor with a breech presentation with no other gross anomaly. However, her aneuploidy screens done before the anomaly scan were low risk. She had no history of fever, urinary tract infection, or leakage per vaginum at that time.

Her subsequent scans also revealed the same liquor status with small bilateral kidneys, done at 30 weeks and 32 weeks of gestation. Pediatric surgery consultation for the fetus was sought at 32 weeks, and they rendered a poor prognosis for the fetus, and the parent couple was counseled about the same. 
Spontaneous onset of labour was awaited till term. The patient was admitted at 41 weeks 2 days of gestation for termination of pregnancy by induction of labour for post-term pregnancy. Her admission ultrasound also showed absent liquor with breech with the fetal cardiac activity present at 140bpm. As her bishop score was 7/13, labour was augmented by oxytocin infusion.

The patient was shifted to the delivery table in the second stage when breech was seen climbing the perineum. With the delivery of breech, it was observed that buttocks were replaced by a single buttock like tissue covering the caudum, followed by delivery of a single lower limb and foot. The back was kept anterior, and the rest of the delivery was conducted by assisted breech delivery. The baby was a fresh stillborn with normal-looking head, thorax, and abdomen, with the following abnormalities:

- Absent external genitalia

- Fusion of lower segment of body below pelvis with fused lower limbs into one with absent buttocks with single anomalous foot with toes spread in a fan like pattern like tail fin of fish (Mermaidlike)

- No urinary meatus

- No anal opening

Birth weight was $1.56 \mathrm{~kg}$ and reflected growth retardation during intrauterine life.Placenta and membranes delivered complete. There were no post-delivery complications and patient was given lactation suppressants. The patient did not consent to take pictures of the baby, and the parent couple was not willing for an autopsy. The infantogram showed continuous soft tissue, including two femurs together in the lower body segment, which continued to have two tibias together and a single foot. The infantogram of the delivered fetus is shown in Figure 1. The patient was counseled adequately in the postpartum period and was discharged the next day.

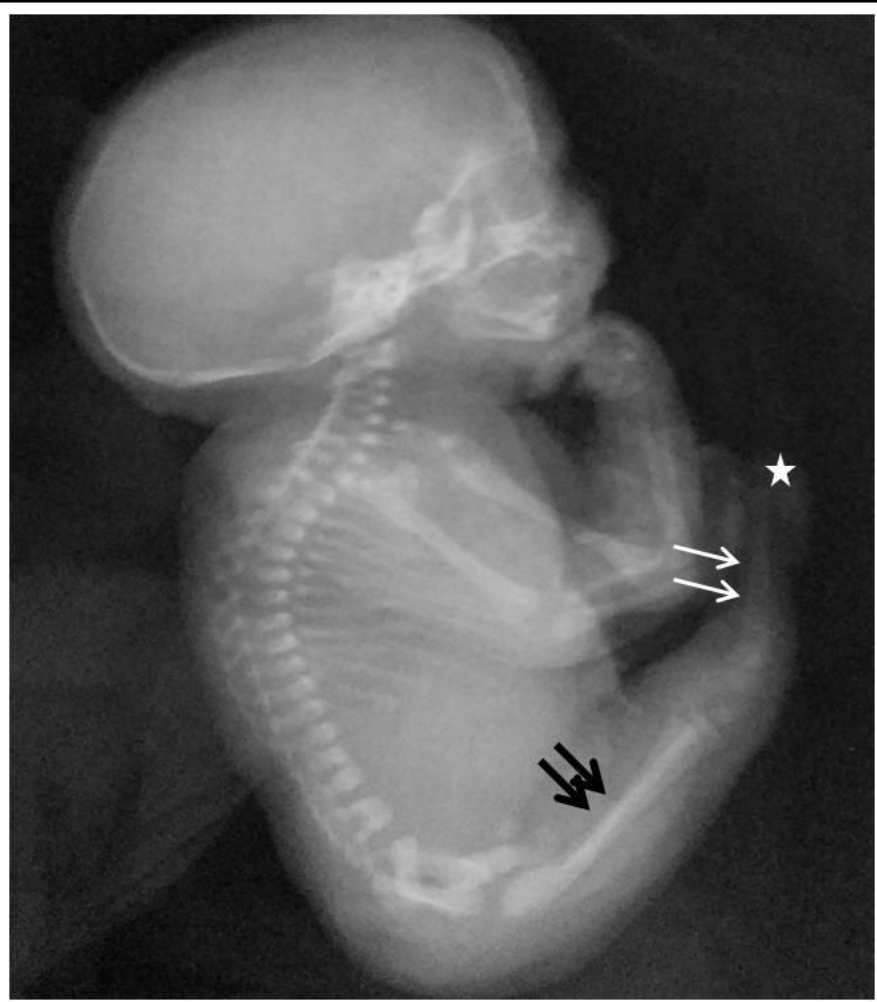

Figure 1: Infantogram shows presence of fused femur (black arrows), fused tibia (white arrows) with single deformed foot (star).

\section{Discussion}

Sirenomelia, also known as the mermaid baby syndrome, is caused due to abnormal development of the lower segment of the body and includes the fusion of bilateral body parts beneath the pelvis, with or without bony defects ${ }^{[5]}$. It is associated with other defects also like renal agenesis or dysgenesis (like in our case), absent genitalia (also was present in our case), cardiac agenesis, vertebral and nervous system defects ${ }^{[6]}$. If a live baby is born, the most common cause of death is due to obstructive renal failure or renal agenesis or dysgenesis. In our case, the fetus had malformed kidneys and urinary system.

The exact cause of this syndrome remains unknown. It has been reported to be associated with twins. Stevenson et al proposed the vascular steal theory. This theory suggests, "There is shunting of blood via an abnormal abdominal artery arising from high up in the aorta towards the placenta. This leaves the caudal part of the embryo poorly perfused. Consequently, there is hypoplasia of the vasculature distal to the artery 
leading to nutritional deficiency of the caudal half of the body leading to complete or incomplete agenesis of caudal structures with in constant lower limb fusion",[8].

Antenatal ultrasound is the predominant diagnostic tool. However, in affected fetuses, bilateral renal agenesis causes early-onset severe oligohydramnios, thus limiting the limb evaluation by ultrasound, and the same happened in our case scenario ${ }^{[9]}$. The syndrome has a poor prognosis, and survival depends on the extent of visceral anomalies. The management of sirenomelia is complex, involves multiple surgical and medical attempts to keep the renal function maintained, though despite the above, the outcome is still unpredictable. It demands substantial financial and physical support to manage sirenomelia conservatively.

Cases of surviving babies have been known. Tiffany Yorks of Clearwater, Florida (May 7, 1988 - February 24, 2016) ${ }^{[10]}$, Shiloh Jade Pepin (August 4, 1999 - October 23, 2009) of Kennebunkport, United States ${ }^{[11]}$, and Milagros Cerrón Arauco (April 27, 2004 - October 24, 2019) of Peru ${ }^{[12]}$; are the famous examples of Mermaid girls who lived for 27, 10 and 15years of lives, respectively. They underwent multiple surgeries in their lifetime.

\section{Conclusion}

Sirenomelia is a rare but interesting syndrome due to its peculiar physical appearance, like the mermaid of Greek mythology. It includes multiple visceral anomalies apart from fused lower limbs. The antenatal diagnosis and termination of pregnancy are advisable. Overall, the disease carries a poor prognosis.

Acknowledgment: We would like to thank Dr. Vikas Bhatia for his help in the preparation of the manuscript.

\section{References}

1. Taori KB, Mitra K, Ghonga NP et al: Sirenomelia sequence (mermaid): report of three cases. Indian $\mathrm{J}$ Radiol Imaging. 2002;12:399-401.

2. Martínez-Frías ML, García A, Bermejo E. Cyclopia and sirenomelia in a liveborn infant. J Med Genet. 1998 Mar;35(3):2634. doi: 10.1136/jmg.35.3.263-a3.

3. Valenzano M, Paoletti R, Rossi A, Farinini D, Garlaschi G, Fulcheri E. Sirenomelia. Pathological features, antenatal ultrasonographic clues, and a review of current embryogenic theories. Hum Reprod Update. 1999 Jan-Feb;5(1):82-6.

4. Garrido-Allepuz C, Haro E, GonzálezLamuño D, Martínez-Frías ML, Bertocchini F,Ros MA. A clinical and experimental overview of sirenomelia: insight into the mechanisms of congenital limb malformations. Dis Model Mech. 2011 May;4(3):289-99

5. Stocker JT, Heifetz SA. Sirenomelia. A morphological study of 33 cases and review of the literature. Perspect Pediatr Pathol. 1987;10:7-50.

6. Tang TT, Oechler HW, Hinke DH, Segura AD, Franciosi RA. Limb body-wall complex in association with sirenomelia sequence. Am J Med Genet. 1991 Oct 1;41(1):21-5.

7. Jaiyesimi F, Gomathinayagam T, Dixit A, Amer M. Sirenomelia without vitelline artery steal. Ann Saudi Med. 1998 NovDec;18(6):542-4.

8. 8.Stevenson RE, Jones KL, Phelan MC, Jones MC, Barr M Jr, Clericuzio C, Harley RA, Benirschke K. Vascular steal: the pathogenetic mechanism producing sirenomelia and associated defects of the viscera and soft tissues. Pediatrics. 1986 Sep;78(3):451-7.

9. Chenoweth CK, Kellogg SJ, Abu-Yousef MMJ, Antenatal sonographic diagnosis of sirenomelia. Clin Ultrasound. 1991 MarApr; 19(3):167-71

10. Tiffany Yorks [@TiffanyYorks] (24 February 2016). "This is Tiffanys cousin 
Jessica Tannehill. Tiffany passed away this morning after a hard fight and she stayed..." (Tweet) - via Twitter.

11. Sammons, Mary Beth (November 26, 2009). "10-Year-Old Girl Born with Legs Fused Together". AOL. Archived from the original on November 26, 2009.

12. "Mermaid" girl takes first steps". BBC News. 28 September 2006. 